\title{
Is BCG Vaccination the Real Angel for India Against Covid19 Infection-A Survey Based on People Perception
}

\author{
Ganesh Lakshmanan ${ }^{1}$, N. Mohamed Arsath ${ }^{2}$, Gheena. $\mathrm{S}^{3}$ \\ Corresponding Email: ganeshl.sdc@ saveetha.com
}

${ }^{1}$ Senior Lecturer, Department of Anatomy, Saveetha Dental College and Hospitals, Saveetha Institute of Medical and Technical Sciences (SIMATS), Chennai, India

${ }^{2}$ Department of Anatomy, Saveetha Dental College and Hospitals, Saveetha Institute of Medical and Technical Sciences (SIMATS), Chennai, India

${ }^{3}$ Associate Professor, Department of oral pathology, Saveetha Dental College and Hospitals, Saveetha Institute of Medical and Technical Sciences (SIMATS), Chennai, India

Received: December 15, $2021 \quad$ Received in Revised: January 20, $2022 \quad$ Accepted: January 26, 2022

\begin{abstract}
The majority of infectious pneumonia associated with the global outbreak covid19 originated in December 2019 in Wuhan, China. Bacille Calmette Guerin (BCG) is a highly pathogenic strain of Mycobacterium bovis that was isolated from the milk of a cow with tuberculosis mastitis following more than 13 years of continuous in vitro passage. BCG vaccination is critical for improving immunity and lowering death rates. The purpose of this research was to determine the efficacy of BCG immunization against covid19 in India. A self-structured questionnaire with ten questions on facts, the role of BCG vaccine, and covid19 was used to conduct an online survey. The questionnaire was created using the online survey platform google forms, and the link was distributed to participants via social media platforms. The findings were analyzed, and using the gathered answers, a descriptive statistical test was run using the statistical program "SPSS version 20," and the outcome was shown in the form of a pie chart. The current research examined public knowledge of the pandemic outbreak and the role of BCG vaccination among the general population. 69.1 percent of respondents are aware of covid19, and 66.2 percent feel that BCG is effective against covid19. Within the constraints of the research, it is concluded that the majority of survey respondents are aware of the BCG vaccination's involvement in avoiding covid19.
\end{abstract}

Keywords: Awareness, BCG vaccine, COVID19, Mortality, Prevention

\section{Introduction}

The most concerning worldwide pandemic pneumonia-associated viral epidemic, covid19, began in December 2019 in Wuhan, China. Tyrell and Bynoe originally reported the new coronavirus in 1966 by culturing virus taken from individuals with a common cold. (1966, Tyrrell \& Bynoe) The World Health Organization classifies the virus as 2019-Ncov, whereas the international council on viral taxonomy classifies the pandemic epidemic as SARS-COV2. The new virus is most likely to have been transmitted by chrysanthemum bats. (Malani \& del Rio, 2020) The coronavirus spreads by direct contact with covid19-positive individuals and also via droplets that remain on surfaces and clothing for many days. Thus, by contacting a contaminated surface or fabric and then touching one's mouth, nose, or eyes, the bacteria or virus that cause covid19 may be transmitted. (Divya et al., 2019) Divya et al. Respiratory problems are among the clinical manifestations. 2020 (Paramasivam et al.). Due to the fact that 
mobile phones are a vital part of society, they pose a significant danger of human to human transmission, since the coronavirus may spread from contaminated surfaces. (2015) (Sriram et al.; Thejeswar \& Thenmozhi, 2015). Cardiopulmonary disorders, for example, are associated with cardiovascular issues (Johnson et al. 2020).

The virus resembles a sphere with spike-like proteins emerging from its surface (Novel Coronavirus Structure Reveals Targets for Vaccines and Treatments, 2020). The new coronavirus spreads by a variety of entrance points, including the neural system. The virus spreads from the mouse, nose, and outer ear to the middle ear via nerves such as trigeminal, facial, and reach muscles such as tensor tympani and stapedius, via numerous foramina (Hafeez \& Others, 2016) Several studies have been published on this topic (Krishna et al., 2016; Pratha \& Thenmozhi, 2016; Seppan et al., 2018). The covid19 from the nose also transmits intracranially through foramina. (Subashri \& Thenmozhi, 2016; Choudhari \& Thenmozhi, 2016; Nandhini et al., 2018; Choudhari \& Thenmozhi, 2016) The virus moves from the mouth, nose, throat, and larynx to the target organ, the lungs, through the eustachian tube. The virus impairs organ and body component function (Menon \& Thenmozhi, 2016) 2016; Samuel \& Thenmozhi, 2015; Kannan \& Thenmozhi, 2015). In underdeveloped nations like as India, the government has taken numerous initiatives to combat the development of covid19 infection, including the analysis and administration of the BCG vaccination. (Gupta \& Dayal, 2020) Globally, chloroquine phosphate, a long-established medicine used to treat malaria, has showed significant effectiveness and is widely approved for the treatment of COVID-19-associated pneumonia. 2020 (Gao et al.). Globally, there is an urgent need to create vaccines that correlate mRNA with individual cells in order to make this tailored spike protein. (Sekar and colleagues, 2019).

Tuberculosis has long been one of the most frequent illnesses in underdeveloped nations such as India. India is ranked 17th among the 22 nations with the highest TB burden in the world. (2015) (Rami et al.). For over a century, the BCG vaccination has been the standard antituberculosis vaccine. (2017) (Thirunavakarasu \& Santhanam) Bovis Mycobacterium Bacille calmettex Guerin is a highly pathogenic strain of Mycobacterium bovis that was isolated from the milk of a cow with tuberculosis mastitis after more than 13 years of continuous in vitro passage (Luca \& Mihaescu, 2013). (Calmette, 1931). BCG vaccination, which has been shown to be effective against TB caused by Mycobacterium tuberculosis, has a detrimental impact on the respiratory system, increasing immunity against covid19, resulting in a decreased death rate. BCG vaccination boosts long-lasting innate immunity against pathogens and plays a nonspecific role in the fight against infection (Kleinnijenhuis et al., 2014).

Throughout its lengthy history, a growing body of data suggests that the BCG vaccination may also have favorable off-target effects, offering some protection against not only certain kinds of tuberculosis but also other illnesses. This is because it seems to aid in immune system stimulation. Given that health organizations worldwide are scrambling to find strategies to treat and prevent the spread of COVID-19 in the absence of a vaccine, some focus has shifted to the $\mathrm{BCG}$ vaccination. The association between $\mathrm{BCG}$ vaccination and covid19 was analyzed in this research, as well as the participants' understanding of the BCG vaccine's function in preventing covid19

\section{Methods}

A self-structured questionnaire was used to conduct an online survey with a sample size of 100 participants drawn from the general community. The questionnaire is divided into two sections. The first section contains questions on the participants' socioeconomic level, facts, and questions that assist raise awareness among the participants. The questionnaire is structured in 
such a way that it contains a variety of questions on the role of BCG vaccine and COVID19. The questionnaire was verified according to established procedures. To minimize sampling bias, measures such as random selection of participants and limiting the participant demographic and age range are used. The questionnaire was created using the internet survey platform " google forms," and the link to it was sent to responders through social media. The replies were recorded, and descriptive analysis, such as the chi-square test, was done on the data using the SPSS statistical software version 20, with the findings of the analytical test reported in the form of pie charts.

\section{Results and Discussion}

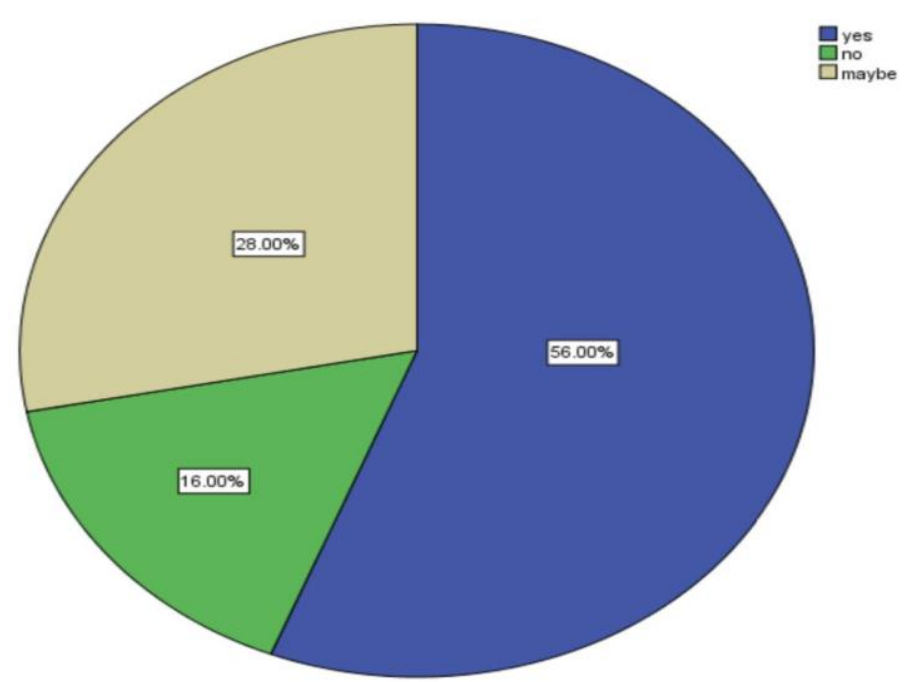

Figure 1. pie chart shows the awareness participants posses regarding the pandemic outbreak covid $19,56 \%$ responded that they are aware of the pandemic outbreak covid 19 (blue),28\% are partially aware of the pandemic outbreak covid19(yellow) and around 16\% unaware(green).

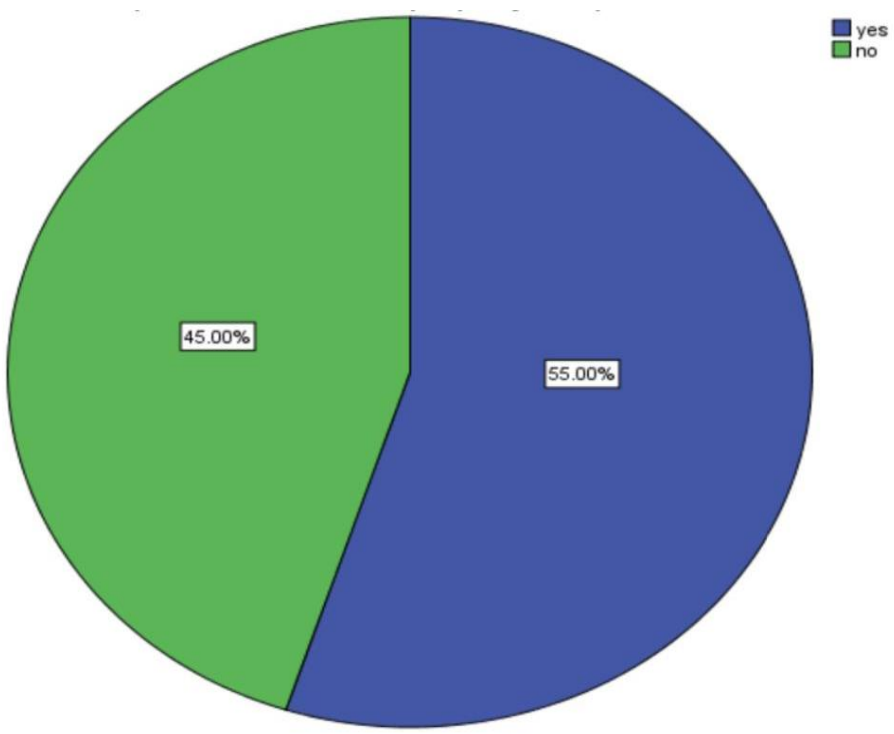

Figure 2. pie chart depicts the knowledge among participants about the various strains of covid19,55\% believe that the virus present in India is less virulent compared to other countries (blue), $45 \%$ of the survey participants disagreed(green). 


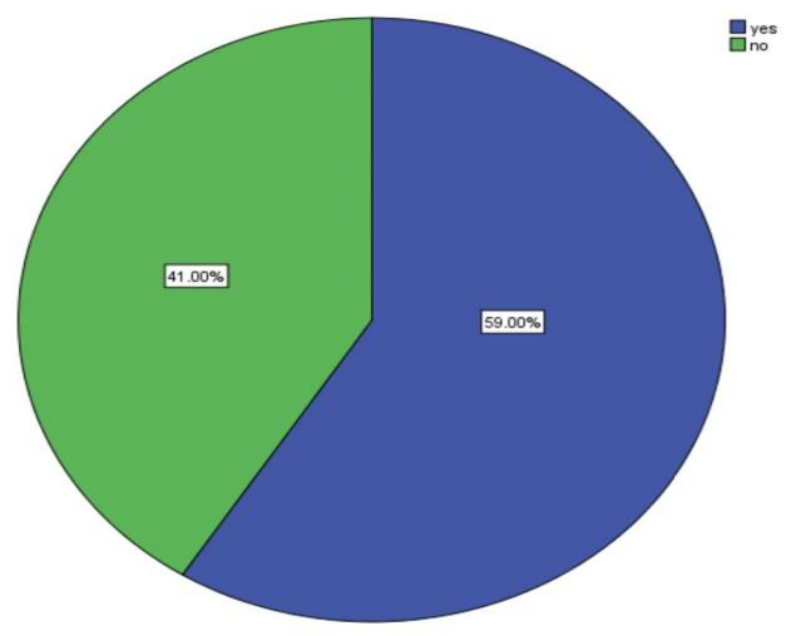

Figure 3. Pie chart depicts the awareness among participants about the BCG vaccine,59\% responded that they are aware of the BCG vaccine (blue), $41 \%$ responded that they are unaware (green)

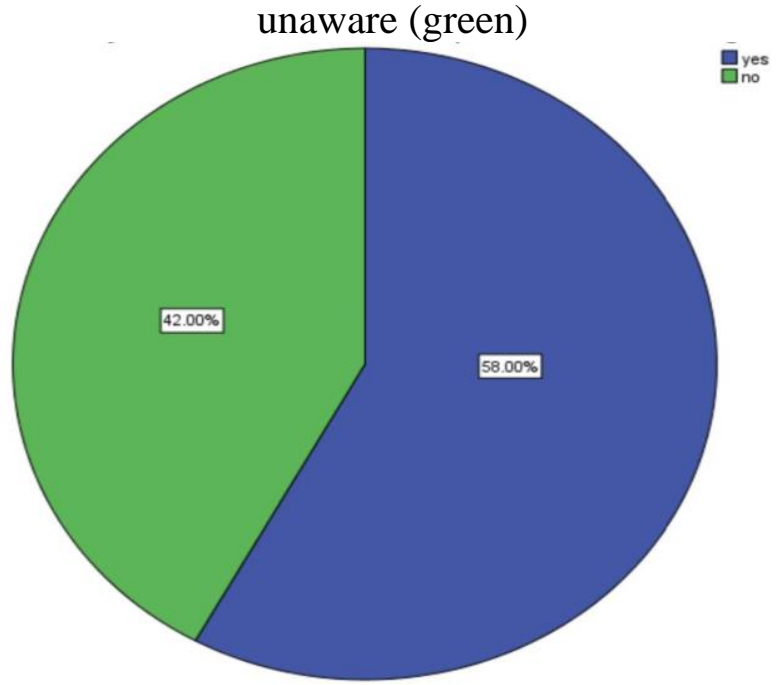

Figure 4. Pie chart reveals knowledge among participants about the effectiveness of BCG vaccine against covid19,58\% believed BCG vaccine is effective against the prevention of covid19 (blue) and around $42 \%$ responded negatively that they are unaware (green).

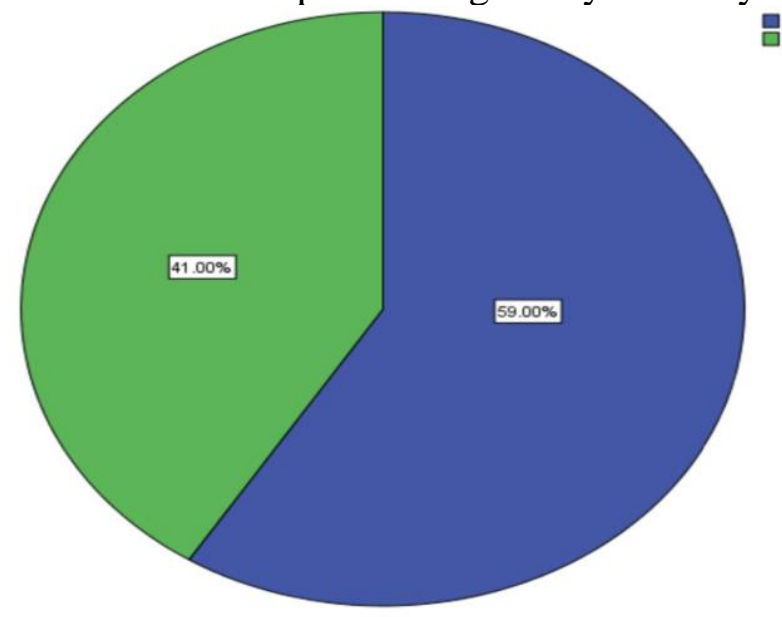

Figure 5. Pie chart depicts the awareness among participants about the method of action shown by BCG vaccine against covid $19,59 \%$ responded positively that they are aware about the method of action (blue), $41 \%$ responded negatively that they are unaware (green).

Copyright (O) 2022, Journal of Asian Multicultural Research for Medical and Health Science Study, Under the license CC BY-SA 4.0 


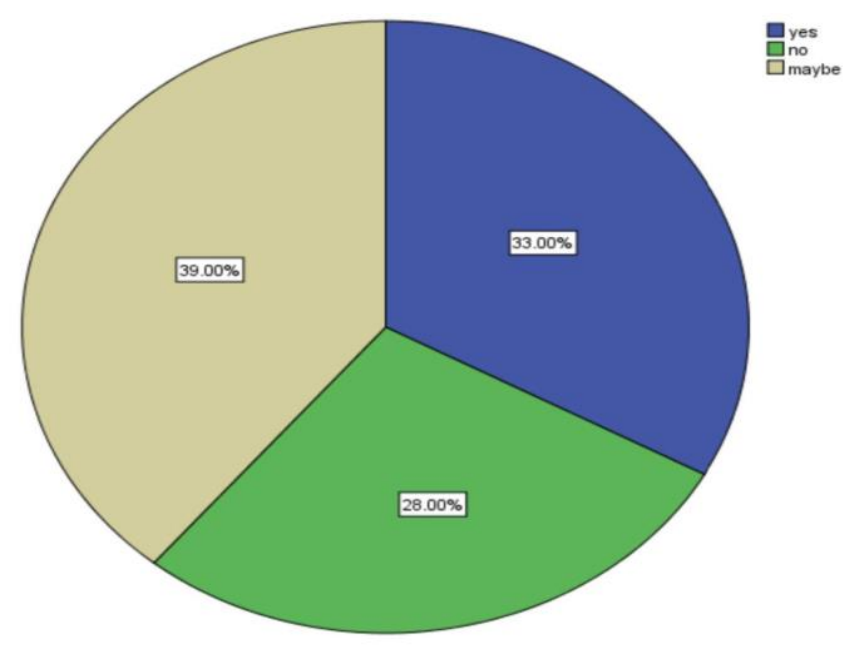

Figure 6. Pie chart depicts the success rate of BCG vaccine in curing patients from covid $19,33 \%$ respondents believe BCG vaccine cure covid19 positive patient (blue),39\% think may be (yellow ),28\% responded negatively (green ).

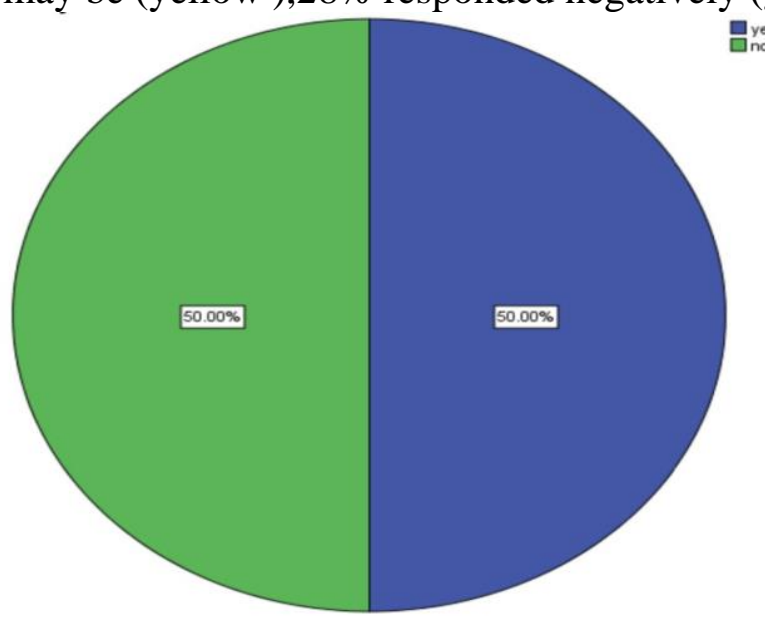

Figure7. Pie chart depicts the result of BCG vaccine in reducing the mortality rate of covid $19,50 \%$ population believe that BCG vaccine has played a significant role in reducing the mortality rate of covid19(blue colour) and 50\% responded negatively (green).

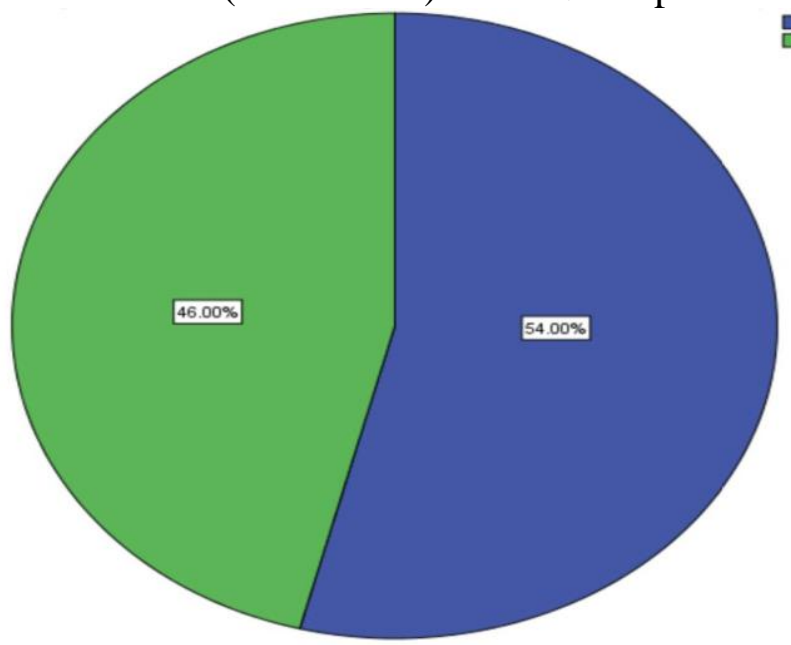

Figure 8. Pie chart depicts the usage rate of BCG vaccine in reducing the spread rate of covid19,54\% believe that BCG vaccine usage reduces the spread rate of covid19(blue) and about $46 \%$ of the participants disagreed(green).

Copyright (O) 2022, Journal of Asian Multicultural Research for Medical and Health Science Study, Under the license CC BY-SA 4.0 


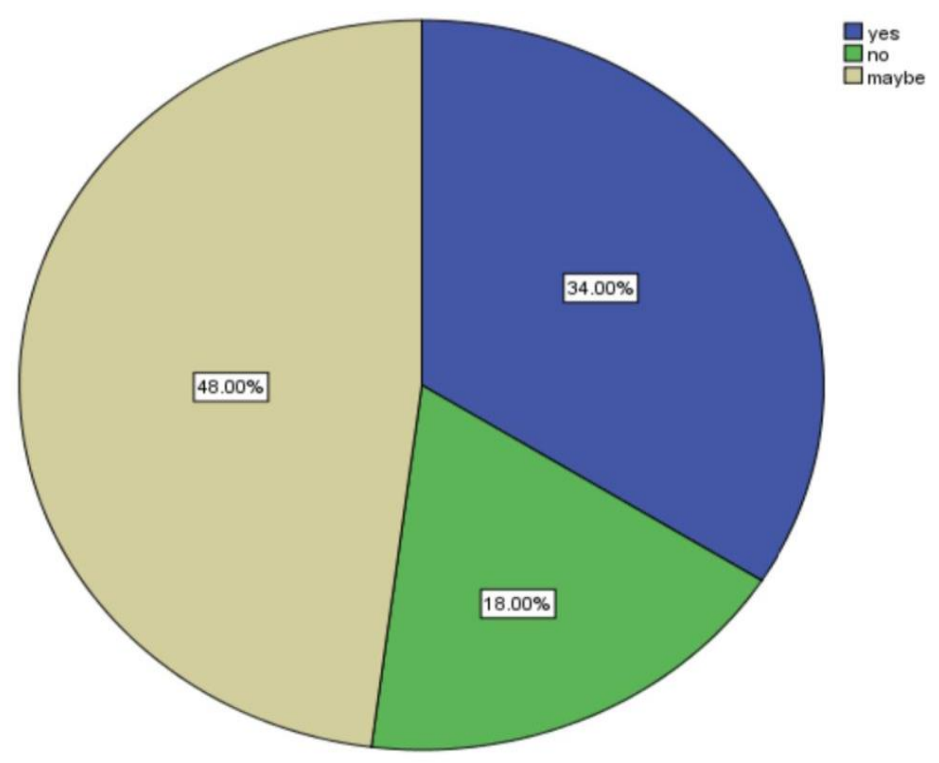

Figure 9. Pie chart shows the role of BCG vaccine in boosting immunity against covid $19,34 \%$ responded positively (blue), $18 \%$ responded negatively(green), $48 \%$ responded that it might be boost immunity (yellow)

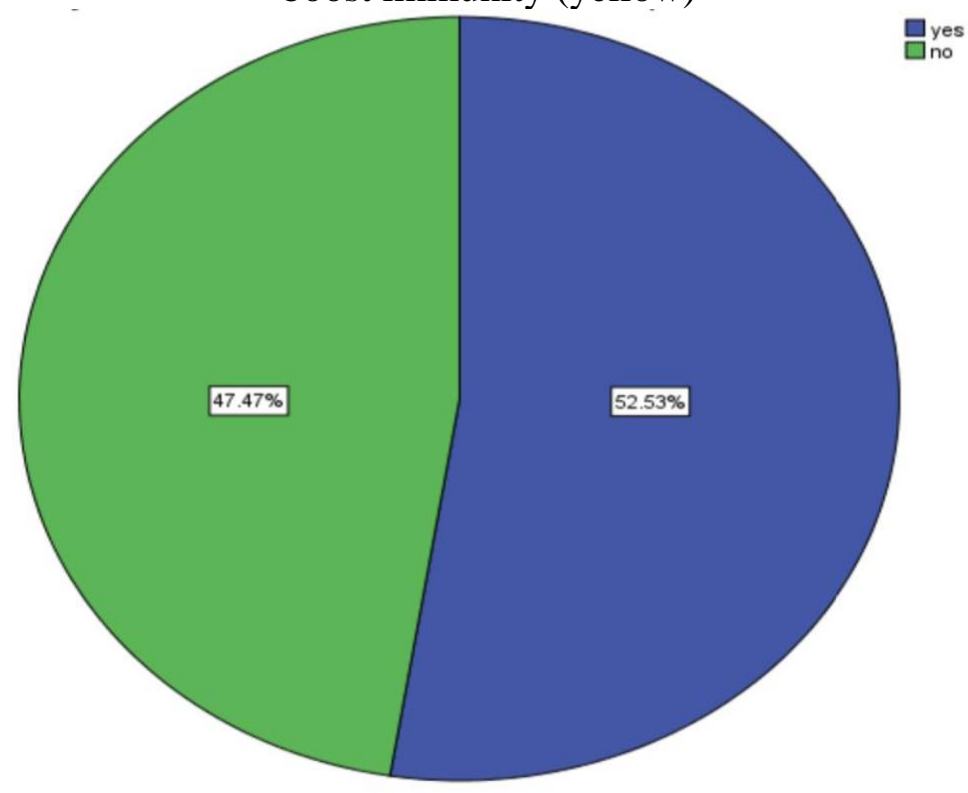

Figure 10. Pie chart shows the responses collected regarding the non specific effect of BCG vaccine in immune system, $52.53 \%$ positive responses(blue) and about $47.7 \%$ negative response (green) 


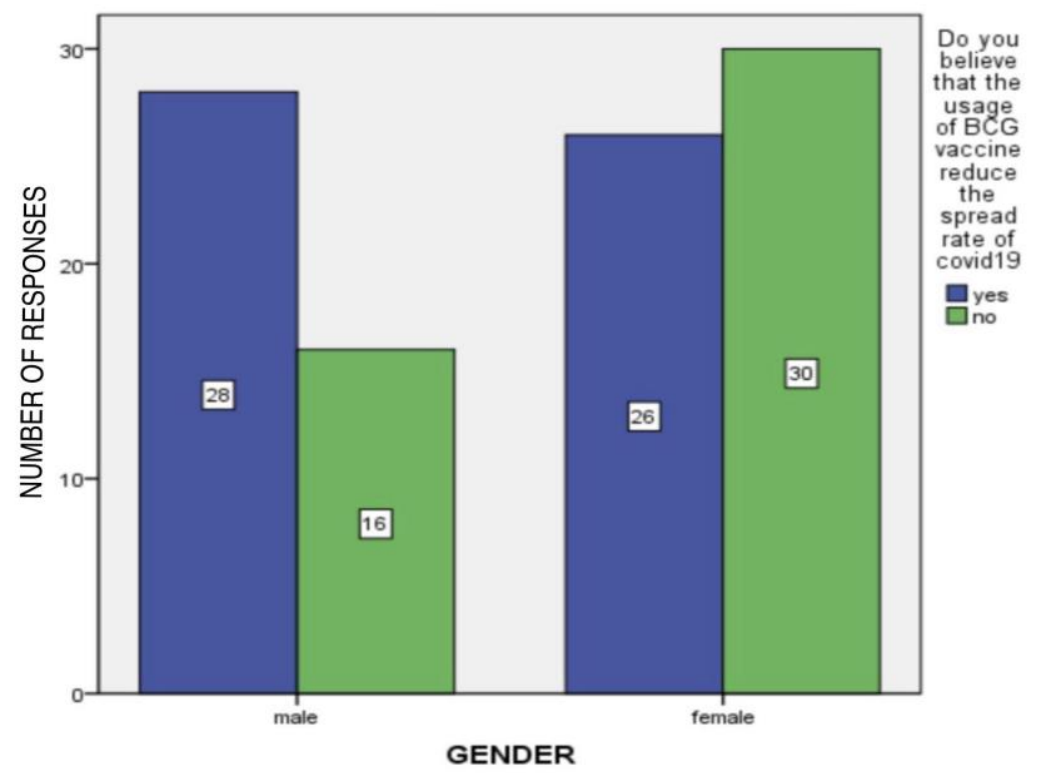

Figure 11. Bar chart showing the correlation between gender and the awareness on the usage of BCG vaccination reduce the spread rate of COVID19.Bar graph represents the individual awareness on usage of BCG vaccine based on gender.X axis represents Gender, $Y$ axis represents individuals who are aware (blue) and unaware (green). Out of 100 participants, 28 male participants were aware whereas only 26 female participants were aware of the same. Though statistically significant males are more aware of the usage of BCG vaccine.Pearson's Chi square analysis $=2.937, \mathrm{DF}-1, \mathrm{P}$ value $=0.087$ and it is not statistically significant.

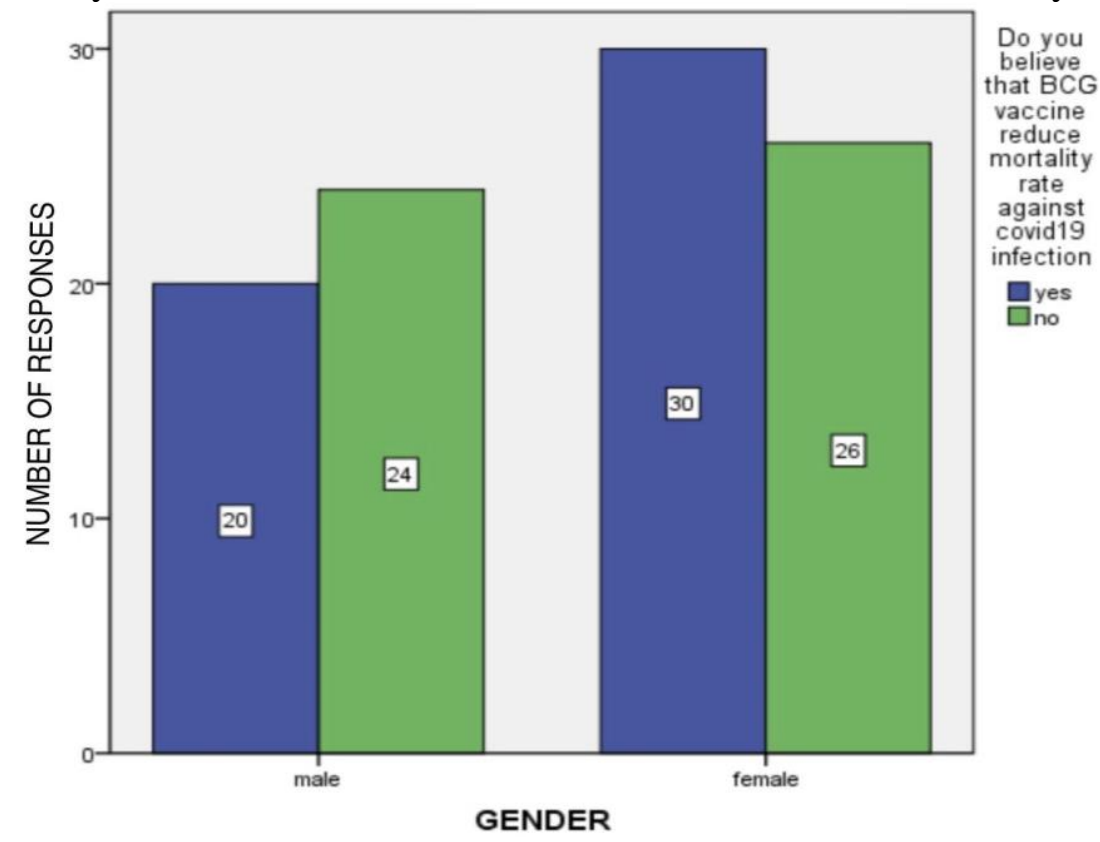

Figure 12. Bar chart showing the correlation between gender and the awareness on the BCG vaccine reduces mortality rate against covid19.X axis represents Gender, $\mathrm{Y}$ axis represents individuals who are aware (blue) and unaware (green). Out of 100 participants, 20 male participants were aware whereas only 30 female participants were aware of the same. Though statistically not significant males are more aware of the global problem of air pollution.Pearson's Chi square analysis $=0.649, \mathrm{DF}-1, \mathrm{P}$ value $=0.420(>0.05)$ and it is not statistically significant. 


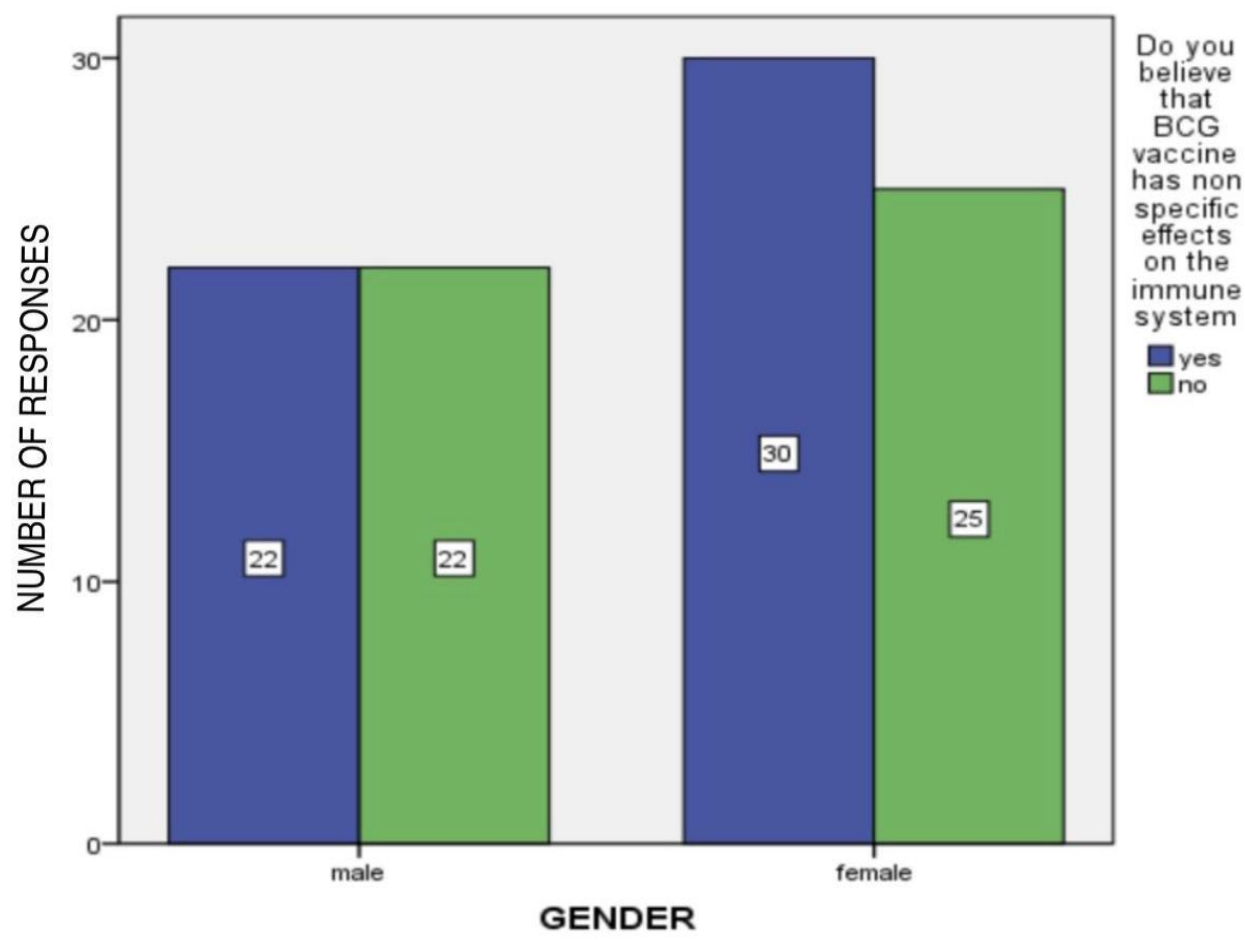

Figure 13. Bar chart showing the correlation between gender and the awareness of the BCG vaccine specific effects on the immune system.X axis represents Gender, $Y$ axis represents individuals who are aware (blue) and unaware (green). Out of 100 participants, 22 male participants were aware whereas only 30 female participants were aware of the same. Though statistically not significant males are more aware.Pearson's Chi square analysis $=0.649, \mathrm{DF}-1$ , $\mathrm{P}$ value $=0.420(>0.05)$ and it is not statistically significant.

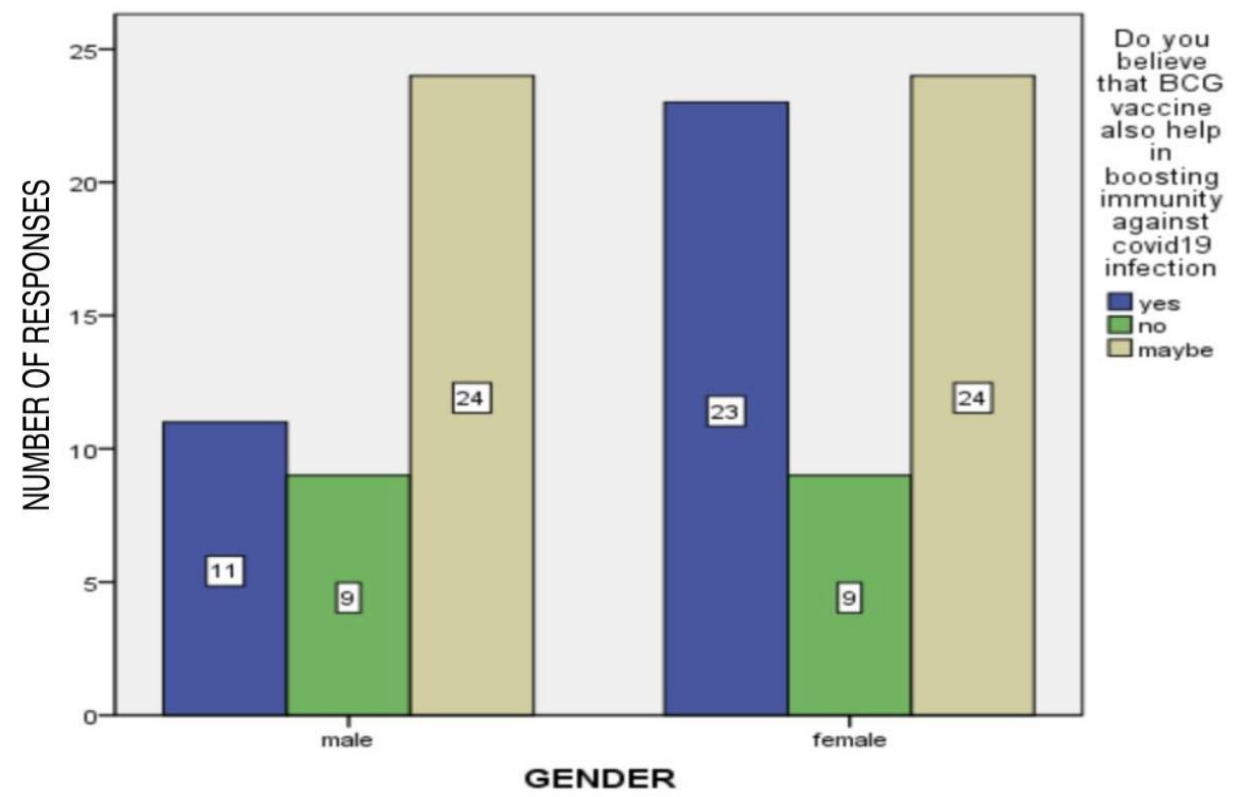

Figure 14. Bar chart showing the correlation between gender and the awareness about the role of BCG vaccine in boosting immunity against covid19 infection. X axis represents Gender, $Y$ axis represents individuals who are aware (blue) and unaware (green). Out of 100

participants, 11 male participants were aware whereas only 23 female participants were aware of the same. Though statistically not significant females are more aware.Pearson's Chi square analysis $=2.386, \mathrm{DF}-2, \mathrm{P}$ value $=0.242(>0.05)$ and it is not statistically significant.

Copyright (0) 2022, Journal of Asian Multicultural Research for Medical and Health Science Study, Under the license CC BY-SA 4.0 
BCG vaccination plays an important role in the prevention of the pandemic outbreak covid19.BCG vaccination is found to reduce the mortality rate and the probability of child being spared from the pandemic outbreak covid19.

The present study was compared to the study done by (dingato et al)proved that $100 \%$ responded that they are aware on covid 19 which was similar to our findings of (fig1) that $69.1 \%$ are aware of the pandemic outbreak and the chi square test performed resulted that $p$ value is less than 0.5 which reveals that the findings of our study is significant (Hu et al., 2020)

Study conducted by(rup lal)discovered that 30 different strains of covid19 are available and the one in India is less virulent in nature compared to the one in countries such as Italy,USA.(US, Italy Strain More Virulent than One in India: Top Indian Microbiologists, n.d.) This finding correlates with our study findings of (fig 2) that $67.8 \%$ responded positively to the questions and the chi square test value is 0.76 which states that the value is greater than $0.05 \%$ so therefore it depicts that the findings of our study are statistically insignificant.

Study conducted by GE packe to evaluate the effectiveness of the BCG vaccine against tuberculosis recorded that $64 \%$ of the patients benefited out of BCG vaccine(Packe \& Innes, 1988). The findings of (fig 3)in the present study correlate the previous study with a similar response stating that $69 \%$ of the people are aware of the role of BCG vaccine against the tuberculosis disease.

The responses recorded for fig4 in the present study shows that $66.2 \%$ believed BCG vaccine is effective against the prevention of covid19 when compared with previous study revealed through analysis that BCG vaccination is one of the trusted prevention methods to prevent healthcare workers against COVID19 infection(Rajarshi et al., n.d.). Fig 5 depicts that $66.2 \%$ of the respondents believe that $\mathrm{BCG}$ vaccination reduces the risk factors associated with covid19. In the current study results of fig6 shows that $42.3 \%$ of the population believe BCG vaccine cures COVID19 positive patients.

Most of the countries with low income levels reported zero deaths attributed to covid19 and in the study it is found that the universal BCG vaccination policies plays a consistent role. The results of this previous study carried out by (Miller et al., n.d.) was in relation with the findings of the present study, (fig 7) depicts that $61.7 \%$ people believe that it reduces the mortality rate and the results of the Chi square test appears to be 0.43 which is greater compared to the standard value so it is very much evident that our findings are statistically insignificant.The results of fig8 depicts that $62.8 \%$ participants are aware about the role of BCG vaccine in reducing the spread rate of covid19.

The fig 9 of the present study reveals that about $40.6 \%$ of the participants believe that BCG vaccine helps in boosting immunity against COVID19(Ozdemir et al., 2020).when compared with one of the previous analysis studies performed proved the impact of BCG vaccination and its relation with immunity to COVID-19.

The fig 10 of the current study shows that around $60.8 \%$ are aware regarding the non specific effect of BCG vaccine in the immune system and the results were Similar to findings of the previous study performed which proved that BCG vaccine possesses a non specific effect on virus and proves to be effective against covid19.(Green et al., n.d.).

\section{Conclusion}

Within the limitation present in our study, the study concludes that most of the survey participants are aware of the role of the BCG vaccination in preventing covid19 and that the

Copyright $@$ 2022, Journal of Asian Multicultural Research for Medical and Health Science Study, Under the license CC BY-SA 4.0 
general people believe that BCG vaccination is one among the criteria in significantly reducing the covid19 impact in developing countries like India.

\section{References}

Calmette, A. (1931). Preventive Vaccination Against Tuberculosis with BCG. Proceedings of the Royal Society of Medicine, 24(11), 1481-1490.

Choudhari, S., \& Thenmozhi, M. S. (2016). Occurrence and Importance of Posterior Condylar Foramen. In Research Journal of Pharmacy and Technology (Vol. 9, Issue 8, p. 1083). https://doi.org/10.5958/0974-360x.2016.00206.7

Dayal, D., \& Gupta, S. (2020). Connecting BCG vaccination and COVID-19: additional data. Medrxiv.

https://www.medrxiv.org/content/medrxiv/early/2020/04/19/2020.04.07.20053272.f ull.pdf

del Rio, C., \& Malani, P. N. (2020). COVID-19-New Insights on a Rapidly Changing Epidemic. JAMA: The Journal of the American Medical Association, 323(14), 13391340.

Divya, R., Senthilnathan, K. P., Kumar, M. P., \& Murugan, P. S. (2019). Evaluation of aerosol and splatter contamination during minor oral surgical procedures. Drug Invention Today, 12(9). http://search.ebscohost.com/login.aspx ?direct=true\&profile=ehost\&scope=site \&auth type $=$ crawler \&jrnl $=09757619 \& A N=138949535 \& \mathrm{~h}=\mathrm{rjB} 1 \mathrm{q} 98 \mathrm{ZKHlH} 4 \mathrm{cba} 8 \mathrm{PCkSLV}$ TwQ7TPyhJ3bKGARmI6UARs3djEY\%2FdB\%2F\%2BPlwrbn\%2BJQvdveXVwJF U\%2FZ0YW29MNYJQ\%3D\%3D\&crl=c

Gao, J., Tian, Z., \& Yang, X. (2020). Breakthrough: Chloroquine phosphate has shown apparent efficacy in treatment of COVID-19 associated pneumonia in clinical studies. Bioscience Trends, 14(1), 72-73.

Green, C. M., Fanucchi, S., Fok, E. T., Simone J C F, Dominguez-Andres, J., Negishi, Y., Joosten, L. A. B., Netea, M. G., \& Mhlanga, M. M. (n.d.). COVID-19: A model correlating $B C G$ vaccination to protection from mortality implicates trained immunity. https://doi.org/10.1101/2020.04.10.20060905

Hafeez, N., \& Others. (2016). Accessory foramen in the middle cranial fossa. Research Journal of Pharmacy and Technology, 9(11), 1880-1882.

Hu, D., Lou, X., Xu, Z., Meng, N., Xie, Q., Zhang, M., Zou, Y., Liu, J., Sun, G., \& Wang, F. (2020). More effective strategies are required to strengthen public awareness of COVID-19: Evidence from Google Trends. Journal of Global Health, 10(1), 011003.

Johnson, J., Lakshmanan, G., M, B., R M, V., Kalimuthu, K., \& Sekar, D. (2020). Computational identification of MiRNA-7110 from pulmonary arterial hypertension (PAH) ESTs: a new microRNA that links diabetes and PAH. Hypertension Research: Official Journal of the Japanese Society of Hypertension, 43(4), 360-362.

Kannan, R., \& Thenmozhi, M. S. (2016). Morphometric Study of Styloid Process and its Clinical Importance on Eagle's Syndrome. In Research Journal of Pharmacy and Technology (Vol. 9, Issue 8, p. 1137). https://doi.org/10.5958/0974360x.2016.00216.x

Kleinnijenhuis, J., Quintin, J., Preijers, F., Benn, C. S., Joosten, L. A. B., Jacobs, C., van

Copyright $@$ (2022, Journal of Asian Multicultural Research for Medical and Health Science Study,

Under the license CC BY-SA 4.0 
Loenhout, J., Xavier, R. J., Aaby, P., van der Meer, J. W. M., van Crevel, R., \& Netea, M. G. (2014). Long-lasting effects of BCG vaccination on both heterologous Th1/Th17 responses and innate trained immunity. Journal of Innate Immunity, 6(2), $152-158$.

Krishna, R. N., Nivesh Krishna, R., \& Yuvaraj Babu, K. (2016). Estimation of stature from physiognomic facial length and morphological facial length. In Research Journal of Pharmacy and Technology (Vol. 9, Issue 11, p. 2071). https://doi.org/10.5958/0974360x.2016.00423.6

Luca, S., \& Mihaescu, T. (2013). History of BCG Vaccine. Maedica, 8(1), 53-58.

Menon, A., \& Thenmozhi, M. S. (2016). Correlation between thyroid function and obesity. Research Journal of Pharmacy and Technology, 9(10), 1568-1570.

Miller, A., Reandelar, M. J., Fasciglione, K., Roumenova, V., Li, Y., \& Otazu, G. H. (n.d.). Correlation between universal BCG vaccination policy and reduced morbidity and mortality for COVID-19: an epidemiological study. https://doi.org/10.1101/2020.03.24.20042937

Nandhini, J. S. T., Thaslima Nandhini, J. S., Yuvaraj Babu, K., \& Mohanraj, K. G. (2018). Size, Shape, Prominence and Localization of Gerdy's Tubercle in Dry Human Tibial Bones. In Research Journal of Pharmacy and Technology (Vol. 11, Issue 8, p. 3604). https://doi.org/10.5958/0974-360x.2018.00663.7

Novel coronavirus structure reveals targets for vaccines and treatments. (2020, March 2). National Institutes of Health (NIH). https://www.nih.gov/news-events/nih-researchmatters/novel-coronavirus-structure-reveals-targets-vaccines-treatments

Ozdemir, C., Kucuksezer, U. C., \& Tamay, Z. U. (2020). Is BCG vaccination affecting the spread and severity of COVID-19? Allergy. https://doi.org/10.1111/all.14344

Packe, G. E., \& Innes, J. A. (1988). Protective effect of BCG vaccination in infant Asians: a case-control study. Archives of Disease in Childhood, 63(3), 277-281.

Paramasivam, A., Priyadharsini, J. V., Raghunandhakumar, S., \& Elumalai, P. (2020). A novel COVID-19 and its effects on cardiovascular disease. Hypertension Research: Official Journal of the Japanese Society of Hypertension. https://doi.org/10.1038/s41440-0200461-x

Pratha, A. A., \& Thenmozhi, M. S. (2016). A study of occurrence and morphometric analysis on meningo orbital foramen. Research Journal of Pharmacy and Technology, 9(7), 880-882.

Rajarshi, K., Chatterjee, A., \& Ray, S. (n.d.). BCG Vaccination Strategy for Preventaion against COVID-19: Hype or Hope? https://doi.org/10.20944/preprints202004.0351.v1

Rami, K., Thakor, N., \& Patel, A. (2015). Awareness and knowledge about tuberculosis in patient of tuberculosis at GMERS Medical College and Hospital Dharpur, Patan, Gujarat. Int J Med Sci Public Health, 4(7), 906-909.

Samuel, A. R., \& Thenmozhi, M. S. (2015). Study of impaired vision due to Amblyopia. Research Journal of Pharmacy and Technology, 8(7), 912-914.

Sekar, D., Lakshmanan, G., Mani, P., \& Biruntha, M. (2019). Methylation-dependent circulating microRNA 510 in preeclampsia patients. Hypertension Research: Official

Copyright (O) 2022, Journal of Asian Multicultural Research for Medical and Health Science Study, Under the license CC BY-SA 4.0 
Journal of the Japanese Society of Hypertension, 42(10), 1647-1648.

Seppan, P., Muhammed, I., Mohanraj, K. G., Lakshmanan, G., Premavathy, D., Muthu, S. J., Wungpam Shimray, K., \& Sathyanathan, S. B. (2018). Therapeutic potential of Mucuna pruriens (Linn.) on ageing induced damage in dorsal nerve of the penis and its implication on erectile function: an experimental study using albino rats. The Aging Male: The Official Journal of the International Society for the Study of the Aging Male, 1-14.

Sriram, N., Thenmozhi, \& Yuvaraj, S. (2015). Effects of Mobile Phone Radiation on Brain: A questionnaire based study. In Research Journal of Pharmacy and Technology (Vol. 8, Issue 7, p. 867). https://doi.org/10.5958/0974-360x.2015.00142.0

Subashri, A., \& Thenmozhi, M. S. (2016). Occipital emissary foramina in human adult skull and their clinical implications. Research Journal of Pharmacy and Technology, 9(6), $716-718$.

Thejeswar, E. P., \& Thenmozhi, M. S. (2015). Educational research-iPad system vs textbook system. Research Journal of Pharmacy and Technology, 8(8), 1158-1160.

Thirunavakarasu, R., \& Santhanam, A. (2017). Knowledge and awareness about tuberculosis among dental students in Saveetha Dental College. Int J Applied Res, 3, 459-462.

Tyrrell, D. A., \& Bynoe, M. L. (1966). Cultivation of viruses from a high proportion of patients with colds. The Lancet, 1(7428), 76-77. 